\title{
Estudo sobre a recepção de produtos transhumanistas no Brasil Study about the reception of transhumanist products in Brazil
}

\author{
Camila L Holanda, Marcelo F Pereira
}

Palavras-chave: Transhumanismo. Ciborgue. Ética. Tecnologias emergentes.

\begin{abstract}
Resumo
Este estudo procura entender o interesse, recepção e opinião do público sobre produtos transhumanistas como implantes e acessórios digitais e aproximar o tema de pessoas que não trabalham nas áreas de tecnologia e design. Ao apresentar modificações como um produto real disponível para consumo, esta pesquisa traz as discussões éticas presentes em contextos técnicos para um âmbito mais informal e cotidiano. Para causar essa aproximação e coletar dados para a análise foi produzido o site da Aeon Cybernetics, uma empresa fictícia que teria chegado ao Brasil em busca de pessoas interessadas em testar os seus produtos. Neste site, os usuários poderiam conhecer os produtos da empresa, sua história e missão e o processo de instalação das modificações oferecidas, além de ler notícias reais relacionadas ao transhumanismo, ver respostas para perguntas frequentes e por fim, se inscrever para adquirir uma modificação. Além do site, foi feita uma divulgação através de redes sociais, que foram utilizadas também como uma ferramenta para entrar em contato com pessoas que estavam interessadas na tecnologia, mas não estavam dispostas a adotá-las. Desse modo, foi possível obter um panorama mais completo sobre a percepção tanto de pessoas que são a favor quanto contra estas tecnologias.
\end{abstract}

Keywords: Transhumanism. Cyborg. Ethics. Emerging Technologies.

\begin{abstract}
This study aims to understand the interest, reception and opinion of the public about transhumanist products such as digital implants and accessories and to approach the subject from the people who do not work in the areas of technology and design. By presenting augmentations as a real product available for consumption, this research brings the discussion about ethics that are present in technical contexts to a more informal context. To do so and collect data for analysis, it was produced a website for Aeon Cybernetics, a fictional company that has arrived in Brazil and is looking for people who are willing to test their products. In this website, the users could read about the products, history and mission of the company, as well as get information about the installation process, read news related to transhumanism and register to get one of the augmentations. It was also created a Facebook page to spread the information and get in touch with people who were interested in the subject, but not willing to adopt one of the products available. It was possible, this way, to obtain a better understanding about the perception of both people who are in favor and against these technologies.
\end{abstract}

\section{Introdução}

O transhumanismo é um assunto recorrente na ficção científica. Seja através de jogos, filmes ou livros, o "projeto de modificar a espécie humana por meio de qualquer ciência emergente, incluindo engenharia genética, tecnologia digital e bioengenharia" (LAGRANDEUR, 2014) é apresentado como a origem de utopias e distopias em diversos mundos ficcionais.

Estas narrativas estão cada vez mais próximas da realidade. Na biologia, a descoberta da CRISPR / Cas9, uma nova ferramenta que permite a edição de genes de forma mais fácil, precisa e barata, impulsiona a criação de espaços como o Genspace, um laboratório coletivo de biotecnologia "Do-it-yourself" localizado em Nova York e produtos como o Glow Gene, um kit caseiro de engenharia genética. Além disso, já é possível imprimir tecidos orgânicos implantados com sucesso em animais, e órgãos com partes eletrônicas integradas.

Com relação a implantes cibernéticos, se destaca a Cyborg Foundation, organização fundada por Moon Ribas e Neil Harbisson, dois autodeclarados ciborgues. A organização se

Anais do $8^{\circ}$ CIDI e 8 CONGIC

Guilherme Santa Rosa; Cristina Portugal (orgs.)

Sociedade Brasileira de Design da Informação - SBDI

Natal | Brasil | 2017

ISBN 978-85-212-1305-5
Proceedings of the $8^{\text {th }} \mathrm{CIDI}$ and $8^{\text {th }}$ CONGIC

Guilherme Santa Rosa; Cristina Portugal (orgs.)

Sociedade Brasileira de Design da Informação - SBDI

Natal| Brazil | 2017

ISBN 978-85-212-1305-5 
dedica a lutar pelos direitos dos ciborgues e dar apoio àqueles que querem expandir seus sentidos por meio da tecnologia. Outro destaque é a empresa Cyborg Nest, que oferece como primeiro produto, já disponível para venda, um sensor chamado "North Sense". Este produto consiste em uma base de titânio instalada no peito do usuário e um sensor que vibra cada vez que ele está de frente para o norte, o que permite que o usuário esteja a todo momento ciente do campo eletromagnético do planeta.

Simultâneo a este desenvolvimento, também surgem dúvidas em relação a segurança, privacidade e ética. A partir da divulgação de documentos confidenciais obtidos por Edward Snowden, foi descoberto um sistema de vigilância global organizado pela Agência de Segurança Nacional americana (NSA, na sigla em inglês), que espionava cidadãos do mundo inteiro, de civis a chefes de estado, através do uso de malware e interceptação de dados de companhias telefônicas e gigantes da tecnologia. Com isso, o debate sobre privacidade e direitos individuais no contexto digital se intensificou e grandes empresas de tecnologia como Google, Facebook e Microsoft passaram a ser alvo de críticas e questionamentos em relação a seus produtos e termos de uso.

Soluções focadas em privacidade como o navegador gratuito Tor, que garante uma navegação anônima ao mover os dados encriptados do usuário por diversos servidores, evitando que sejam rastreados, e o site de busca Duck Duck Go, que oferece uma alternativa ao Google que não coleta dados pessoais ou de uso, ganham mais adeptos. Além disso, usuários passam a criar contas secretas em redes sociais e utilizar fita adesiva para bloquear webcams que não estão em uso, em uma tentativa de proteger seus dados digitais de acessos não autorizados.

Por conta deste contexto, surgem questões: como os designers, cientistas e outros profissionais envolvidos com o transhumanismo lidam com os aspectos éticos destes novos produtos? Existem leis que regulam o desenvolvimento destas tecnologias? Estas leis são necessárias? A quem elas beneficiam?

Ao frequentar palestras, oficinas e ambientes de desenvolvimento referentes às tecnologias citadas, estas dúvidas se intensificam. Na oficina "CRISPR Workshop: Beyond the Hype", realizada em março de 2016 no Genspace NYC, foi citado o caso de um cientista que criou uma mosca com genes que se sobrepõem aos genes originais durante a procriação. Em meio a discussões, um dos presentes propôs a inserção de insetos que utilizam a mesma tecnologia na natureza, sem considerar consequências e o impacto que isto poderia causar no bioma. No momento, não há nenhuma regulamentação que o impediria de fazer isso.

Esta discussão, porém, ainda está restrita aos meios acadêmico e científico. A partir de reflexões sobre a ética e a responsabilidade de estar à frente do desenvolvimento de tecnologias emergentes e invasivas como as citadas, surgiu a proposta desta pesquisa: aproximar o transhumanismo e as tecnologias que o possibilita de pessoas que não estão em contato diário com a área, apresentando modificações como um produto real disponível para consumo e buscando trazer a discussão para um âmbito mais informal ao testar o interesse, recepção e opinião do público sobre o tema.

Esta pesquisa busca responder às seguintes questões: a população que não está inserida no contexto técnico apresentado tem conhecimento do nível atual de desenvolvimento destas tecnologias e do impacto que elas podem causar? Como elas reagiriam caso essas novas possibilidades estivessem facilmente acessíveis? E quais seriam suas principais preocupações?

Para causar essa aproximação e coletar dados para análise foi produzido o site da Aeon Cybernetics, uma empresa fictícia que acaba de chegar ao Brasil e está à procura de usuários dispostos a testar seus produtos: modificações que tem como objetivo expandir os sentidos e possibilidades humanas por meios artificiais.

Além de um site contendo um questionário através do qual os usuários poderiam se inscrever para obter os produtos apresentados, também foi criada uma página da empresa no Facebook, o que possibilitou a divulgação e entrevistas com usuários que não haviam se inscrito no site.

\section{Metodologia}

\section{Criação da Aeon Cybernetics}


A primeira parte da pesquisa foi dedicada ao desenvolvimento da Aeon Cybernetics. Era fundamental que a empresa transmitisse confiança e veracidade, portanto foram criadas uma identidade visual, história da empresa, sua missão e motivo para que estivesse lançando seus produtos no Brasil.

Segundo o site, a empresa tem como objetivo aproximar os avanços atuais em biotecnologia do dia a dia. Criada em 1984, desenvolveu diversos projetos utilizando sensores implantáveis, edição de código genético e tecnologia vestível, com o objetivo de explorar a interseção entre biologia e tecnologia. Em 2014, se especializou no comércio e divulgação de produtos de biotecnologia, com o objetivo de fornecer estes produtos de forma menos técnica e burocrática.

A empresa justifica a presença no Brasil através de estatísticas da Secretaria de Comunicação Social, que comprovam que brasileiros tem uma relação intensa com a tecnologia, sendo responsáveis por $10 \%$ de todo o tempo gasto em redes sociais no mundo. Além disso, a pesquisa também mostra que a grande maioria dos usuários acessa a internet diariamente, passando em média 5 horas por dia online e se interessam e adotam com facilidade novos dispositivos eletrônicos, sendo assim o público ideal para a divulgação de uma nova tecnologia.

Os 6 produtos criados para a pesquisa foram derivados de modificações que já existem atualmente, seja para uso comercial ou em fase de testes. Os produtos foram organizados nas categorias a seguir:

Praticidade: Infinite ID e Covert Sound. O Infinite ID é baseado em um chip NFC e permitiria ao usuário abrir portas sem precisar de chave e carregar suas informações pessoais dentro da sua pele, mais especificamente entre o dedo indicador e o polegar de uma das mãos. O Covert Sound consistiria em ímãs implantados nas orelhas que possibilitam ao usuário ouvir sons sem fones de ouvido, e foi baseado no trabalho de Rich Lee, que implantou ímãs em seus próprios ouvidos para o mesmo objetivo.

Saúde: CyberFit e Health Aid. Cyberfit seria um sensor que adere ao torso para monitorar sinais vitais, hidratação e nutrientes. Foi baseado no sensor GraphWear, um adesivo que adquire este tipo de informação através do suor do usuário. Health Aid seria uma pílula que, em conjunto com um adesivo digital, registra a frequência em que o usuário tomou seu remédio, entre outras informações como pressão sanguínea e ritmo cardíaco. Este produto foi baseado no sistema de saúde Proteus, que contém sensores ingeríveis.

Novos sentidos: Neo Touch e Earth Link. O Neo Touch seria um ímã que quando implantado no dedo permite que o usuário sinta ondas eletromagnéticas e mova pequenos objetos metálicos. Foi baseado em uma das modificações mais populares atualmente, implantes de ímãs geralmente localizados no dedo anelar. O Earth Link é um ímã instalado no peito que permite que a pessoa sinta o campo magnético da terra, funcionando como uma bússola. Ele é baseado no North Sense, citado anteriormente neste artigo.

\section{Desenvolvimento do site e questionário}

Após desenvolver o conceito da empresa, foi criado um site oficial para divulgar os produtos e coletar informações através de um questionário de inscrições. O site foi formado por 7 páginas:

Página inicial, contendo textos que ilustram como seria o dia-a-dia de alguém que utiliza os produtos criados

Como Funciona, que explica como obter e instalar as modificações

Produtos, que descreve cada um dos 6 produtos em detalhes

Perguntas Frequentes, que contém respostas para as perguntas mais recebidas durante 0 processo de concepção do estudo

Notícias, com diversas notícias reais relacionadas a transhumanismo pelo mundo

Sobre, contendo a história e missão da empresa, bem como o motivo para ela estar no Brasil Inscreva-se, com o questionário utilizado para inscrições no processo seletivo da empresa

Caso o usuário optasse por se inscrever no processo seletivo para adquirir os produtos da empresa, ele precisaria preencher um questionário com as seguintes perguntas: 
Gênero

Data de nascimento

Quais modificações mais te interessam?

O que te motiva a obter as modificações selecionadas?

Você possui dúvidas ou preocupações a respeito do processo? Quais?

Há alguma modificação que você deseja, mas não oferecemos ainda?

Além disso, o usuário poderia fornecer o endereço de e-mail, caso desejasse.

Estas perguntas tem como objetivo traçar o perfil das pessoas que estão dispostas a adotar essas tecnologias e descobrir se gênero e faixa etária são relevantes nessa decisão, se o interesse está atrelado a alguma necessidade (como um problema de saúde), se aceitaria estas modificações apenas para ter uma habilidade ou sentido extra, se há algo que o impediria de prosseguir com a utilização e qual o nível máximo de intrusão que a pessoa estaria disposta a aceitar.

Para validar estas informações, ao final do questionário havia um link para os termos de uso, onde constava o fato de o site fazer parte de uma pesquisa acadêmica. Para enviar as respostas, era obrigatório que os usuários afirmassem estar de acordo com estes termos. Este requerimento foi utilizado por questões éticas, para garantir que as pessoas que respondessem o questionário soubessem que não havia possibilidades reais de eles obterem os produtos divulgados.

\section{Divulgação em redes sociais}

Para divulgação, foi criada uma página da Aeon Cybernetics no Facebook, na qual foram publicadas as notícias que estavam no site principal, variando entre o desenvolvimento de novos dispositivos, novidades médicas e científicas e notícias da empresa. Para garantir que a pesquisa alcançasse pessoas de vários perfis, contextos e idades diferentes, duas publicações foram "impulsionadas", termo usado pelo Facebook para propagandas patrocinadas.

A primeira notícia a ser impulsionada teve como título: "Aeon Cybernetics abre inscrições para teste de novas modificações corporais", e tinha como objetivo entender quantas pessoas se interessavam pela possibilidade oferecida. Ela foi direcionada para homens e mulheres de 18 a 65+ anos, que moram no Brasil e que tinham entre os interesses tópicos relacionados a tecnologia e jogos. Para esta publicação, foram investidos $R \$ 50,00$ ao longo de 7 dias.

A segunda notícia teve como título "Futurista prevê que conexão entre o cérebro humano e a inteligência artificial acontecerá nos próximos 15 anos" e tinha como objetivo entender qual o nível de interesse pelo tema. Esta notícia foi direcionada para o mesmo público, porém com um investimento de $\mathrm{R} \$ 10,00$ ao longo de um dia e, em uma tentativa de excluir pessoas mais jovens que o público alvo desejado, foram excluídos do alcance aqueles que trabalhavam ou estudavam na "VASP - Vagabundos Anônimos Sustentados pelos Pais", uma empresa fictícia popular entre os adolescentes que não tem uma profissão.

Após a divulgação, todos os usuários que interagiram com as publicações foram convidados para curtir a página. Aqueles que curtiram receberam a mensagem abaixo através do chat do Facebook, sendo selecionados para a entrevista os 7 que aceitaram a proposta.

Oi [nome do usuário], tudo bom? Sou da Aeon Cybernetics, empresa que vende modificações e acessórios tecnológicos para o corpo. Notamos que você curtiu nossa publicação aqui no Facebook e selecionamos você para participar de uma pesquisa acadêmica que busca entender um pouco melhor a sua opinião sobre a nossa proposta e tirar eventuais dúvidas. Basta responder algumas perguntas simples, fáceis e rápidas. E não se preocupe, é possível desistir a qualquer momento. Você topa? Obrigada pela atenção!

\section{Entrevistas}

Para a entrevista, foi feito um roteiro que tinha como objetivo tentar entender quais foram as impressões e pensamentos das pessoas que curtiram a página e as matérias, mas não haviam 
se inscrito no site, assim como o porquê de elas não terem se inscrito. A primeira parte da entrevista foi feita com base nas perguntas a seguir:

O que te chamou a atenção na página?

Você chegou a dar uma olhada nos produtos? Se interessa por algum deles?

Como você imagina que seja o processo?

Você toparia colocar algum desses produtos?

Tem alguma dúvida sobre o processo e a empresa?

Após entender porque os entrevistados se interessaram pela Aeon, e os motivos pelos quais eles não haviam se inscrito para o teste, foi revelado que a empresa era apenas parte de uma pesquisa acadêmica e que os produtos não seriam oferecidos de verdade. Isto fez com que os entrevistados sentissem mais liberdade para responder às últimas perguntas:

Qual a primeira impressão com relação à empresa?

Teve receios? Quais? No que pensou?

Você chegou a conversar com outras pessoas sobre esses produtos? Como eles reagiram?

Estas perguntas ajudaram a traçar um perfil mais completo com relação às atitudes e pensamentos que as pessoas tem quando se deparam com uma tecnologia intrusiva e desconhecida.

\section{Recepção do público e análise das informações}

\section{0 interesse existe?}

O interesse do público pelo tema pode ser medido, primeiramente, pela taxa da engajamento nos posts do Facebook. A primeira publicação, que convidava os usuários a se inscrever para obter as modificações teve um alcance de 2.634 pessoas e 508 envolvimentos em uma semana, entre curtidas e reações. A segunda publicação, uma notícia sobre as previsões de um futurista, teve um alcance de 678 pessoas e 114 envolvimentos, em um dia.

Para comparação foi utilizada a ferramenta Barometer, que compara a performance de uma página do Facebook com a média de páginas registrada em seu sistema. O nível de engajamento (definido pelo número de curtidas, comentários, compartilhamentos e cliques em relação à quantidade de usuários alcançados pelo post) da página é de $23.3 \%$, bem maior do que a média de outras páginas, $6.3 \%$. Este número indica que o tema do transhumanismo é de interesse e chama a atenção da maior parte dos usuários alcançados.

No entanto, outra taxa que chama a atenção é a taxa de cliques (em relação a todos os posts), $0.4 \%$, baixa em comparação com a média de $2.3 \%$ da ferramenta. Ao analisar mais a fundo, podemos perceber uma grande diferença da porcentagem dos cliques na postagem das inscrições (20 cliques de 2.634 pessoas alcançadas, $0.75 \%$ ) e das notícias (10 cliques entre 678 pessoas, $1.47 \%$ ), o que pode indicar que, apesar do interesse, as pessoas alcançadas pelo Facebook ainda não estão dispostas a adotar a tecnologia, teoria comprovada através das entrevistas realizadas.

Com relação ao site, de acordo com o Google Analytics foram 118 visitantes únicos, dos quais $6(5.08 \%)$ deles se inscreveram para testar as modificações. Os usuários visitaram em média 2,71 páginas por sessão, o que indica um bom nível de interesse pelas informações disponíveis no site, que possui no total 7 páginas.

Pelo que eles se interessam?

Entre os 9 usuários interessados nas modificações, a Covert Sound foi a modificação mais popular, com 6 usuários querendo adotá-la. Em seguida vem a NeoTouch, com 5 usuários, CyberFit e EarthLink com 4, HealthAid com 3 e por último InfinitelD, com 2 usuários.

Com relação aos motivos que os levam a buscar estas modificações, as respostas foram variadas: 


\section{CIDI2017 ${ }^{-g^{\mathrm{h}} \mathrm{CIDI}}$

"Eu sinto que como ser humano devo buscar superar os limites estabelecidos previamente à minha existência" (homem, 24)

"tenho históricos de doenças cardíacas, diabetes e câncer na família e, portanto, me preocupo demais com a minha saúde" (mulher, 23)

"Não ter de depender de aparelhos de GPS é uma coisa muito interessante" (homem, 22)

"Praticidade" (homem, 24)

É interessante notar que todos os 6 inscritos tem idade entre 22 e 26 anos. Dos entrevistados via Facebook, apenas um dos 3 que optaram por uma das modificações tem idade acima dos 30 anos.

\section{Dúvidas e receios}

Tanto entre os usuários entrevistados quanto entre os usuários inscritos, as dúvidas e receios podem ser divididos em 3 pontos principais:

\section{Legitimidade da empresa}

A confiança na Aeon Cybernetics como instituição foi um dos pontos mais relevantes para os usuários. Como a empresa não possuía uma presença pré-estabelecida na internet por meio de perfis públicos ou notícias, alguns usuários acharam que se tratava de um golpe, o que foi intensificado pela sensação de insegurança presente no país.

"Eu fui pesquisar sobre, etc, pra saber a legitimidade, porque a maior preocupação era mesmo só isso, ver se vocês eram uma empresa legítima (...) o Brasil é fogo" ( homem, 22)

"Por um acaso uma amiga me enviou um convite para curtir a página de vocês, como sempre faço quando recebo tais solicitações, faço sempre um busca rápida a respeito do serviço, produto, conteúdo e por aí vai" (homem, 21)

"Eu pensei que vocês eram pessoas erradas, que iam tirar alguma parte do meu corpo" (mullher, 18 anos)

\section{Acesso}

Outro assunto presente nas entrevistas foi a dificuldade de acesso aos produtos, especialmente pela distância física. Os 3 entrevistados que não moravam em grandes capitais como Rio de Janeiro e São Paulo se preocuparam com a logística por trás da instalação dos produtos. Esta desconfiança pode ser considerada também um reflexo da dificuldade de acesso à infraestrutura e tecnologia no país.

"Vcs moram longe" (mulher, aproximadamente 40 anos)

"Mas como eu poso esprerimenta si eu mora aqui em Camocim Ceará não dá meu anjo" (homem, 39 anos)

\section{Efeitos colaterais}

A maior preocupação entre os inscritos e entrevistados foi, no entanto, o possível impacto que os implantes teriam na sua saúde, incluindo efeitos colaterais, rejeição ao equipamento e reações não previstas.

"isso pode causar algum dano corporal" (homem, aproximadamente 20 anos)

"Tenho medo do meu corpo não se adaptar ao processo e de desejar retirar o implante e não ser possivel" (mulher, 22)

"como se trataria qualquer problema envolvendo essas tecnologias em um corpo humano com um plano de saúde normal?" (homem, 22)

"NeoTouch parece ter efeitos constantes e permanentes, o que pode gerar situações insatisfatórias como objetos se magnetizando a mim contra minha vontade, sem a possibilidade de "desligar" a modificação" (homem, 23) produtos.

Não houve perguntas sobre os aspectos éticos ou de privacidade da empresa e dos 


\section{Considerações finais}

Através desta pesquisa é possível supor que produtos transhumanistas geram um grande interesse na população, mas que o medo de que estes produtos prejudiquem o corpo é grande o bastante para que muitos desistam de adotar a tecnologia. Aspectos como privacidade e segurança digital, frequentemente discutidos por especialistas da área, não parecem ser uma preocupação relevante para a população geral.

Esta aparente ausência de preocupação pode ser motivada por ignorância em relação aos riscos envolvidos, ou pela relação dos usuários com a tecnologia atualmente: em meio a divulgação de diversos momentos da vida em redes sociais, muitas vezes de maneira excessiva, a própria noção de privacidade nos meios digitais pode parecer dispensável. Além disso, a sensação de anonimato e ausência de consequências pode fazer com que as pessoas sintam que estão protegidas de problemas online, e que basta se desconectar para que nada daquilo tenha acontecido.

"Assim que vocês mostrassem competência, um ambiente maneiro, eu não ia duvidar não" (homem, 22)

Em vez disso, há uma preocupação maior com a parte prática: como o produto chegará até as pessoas, quanto custa, o que acontece caso não funcione e que garantias a empresa daria. Estas preocupações são compreensíveis, especialmente considerando o contexto do país: altos impostos, dificuldades em infraestrutura e logística e mais de 2,5 milhões de consumidores atendidos por ano pelo Procon, em todo o país.

É importante notar que o preço destes produtos dependerá da forma como o governo classificará os mesmos. Os produtos utilizados neste estudo podem se enquadrar em diversas categorias: saúde, entretenimento, praticidade. Caso sejam considerados fundamentais para a população, podem receber taxas menores de imposto, podendo inclusive se enquadrar na "Lei do Bem", que concede isenções fiscais para pessoas jurídicas que realizarem pesquisa e desenvolvimento de inovação tecnológica.

Por fim, esta pesquisa não questiona a utilidade ou os benefícios trazidos por essas modificações, mas sim a recepção da população atual a estes produtos. Uma vez que a empresa a oferecer este tipo de tecnologia consiga fornecer os produtos a um preço acessível, com um bom suporte ao consumidor e presença em diferentes áreas do país incluindo possíveis parcerias com médicos, hospitais ou, dependendo do produto, estúdios de body piercing, a adoção da tecnologia deve acontecer de maneira rápida.

\section{Bibliografia Consultada}

LAGRANDEUR, Kevin. What is the Difference between Posthumanism and Transhumanism? disponível em: <https://ieet.org/index.php/IEET2/more/lagrandeur20140729> Acesso em 12 out. 2016

CRISPR: A game-changing genetic engineering technique. Disponível em: $<$ http://sitn.hms.harvard.edu/flash/2014/crispr-a-game-changing-genetic-engineeringtechnique/> Acesso em 29 jun. 2017

Genspace disponível em <https://www.genspace.org>Acesso em 12 out. 2016

GlowGene: The Genetic Engineering laboratory Disponível em: <https://www.kickstarter.com/projects/glowgene/glowgene-create-new-lifeforms-by-mixing-updna> Acesso em 12 out. 2016

MUN CHING, Lee. 3D Bioprinting: how close are we to printing our organs from a desktop printer? disponível em<http://www.openbiomedical.org/3d-bioprinting-close-are-we-to-printingour-organs-from-desktop-printer/> Acesso em 29 jun 2017 
12 Things We Can 3D Print in Medicine Right Now disponível em:

<https://3dprintingindustry.com/news/12-things-we-can-3d-print-in-medicine-right-now-42867/> Acesso em 29 jun 2017

Cyborg Foundation disponível em: <http://www.cyborgfoundation.com> Acesso em 12 out. 2016

Cyborg Nest disponível em: <https://cyborgnest.net> Acesso em 12 out. 2016

NSA Files: Decoded - What the revelations mean for you. disponível em:

<https://www.theguardian.com/world/interactive/2013/nov/01/snowden-nsa-files-surveillancerevelations-decoded\#section/1> Acesso em 29 jun. 2017

FRANCESCHI-BICCHIERAI, Lorenzo The 10 Biggest Revelations From Edward Snowden's Leaks disponível em <http://mashable.com/2014/06/05/edward-snowdenrevelations/\#oESSKy60KPqx> Acesso em 29 jun. 2017

Tor - Anonymity Online disponível em: <https://www.torproject.org> Acesso em 29 jun. 2017

Duck Duck Go disponível em: < https://duckduckgo.com> Acesso em 29 jun. 2017

LORENZ, Taylor The secret Instagram accounts teens use to share their realest, most intimate moments disponível em < https://mic.com/articles/175936/the-secret-instagramaccounts-teens-use-to-share-their-realest-most-intimate-moments\#.oXmW1 miDj> Acesso em 29 jun. 2017

LECHER, Colin Mark Zuckerberg tapes up his webcam disponível em < https://www.theverge.com/2016/6/21/11995032/mark-zuckerberg-webcam-tape-photo> Acesso em 29 jun. 2017

HESMAN SAEY, Tina. Gene drives spread their wings disponível em <https://www.sciencenews.org/article/gene-drives-spread-their-wings> Acesso em 29 jun. 2017

KUZMA, Jennifer. Policy: Reboot the debate on genetic engineering disponível em < https://www.nature.com/news/policy-reboot-the-debate-on-genetic-engineering-1.19506> Acesso em 29 jun. 2017

SECRETARIA DE COMUNICAÇÃO SOCIAL DA PRESIDÊNCIA DA REPÚBLICA. Pesquisa Brasileira de Mídia 2015 Disponível em: http://www.secom.gov.br/ atuacao/pesquisa/lista-depesquisas-quantitativas-e-qualitativas-de-contra- tos-atuais/pesquisa-brasileira-de-midia-pbm2015.pdf Acesso em 12 out. 2016

TOZETTO, Cláudia. Vendas de tablets vão superar as de notebooks no Brasil. Disponível em: http://veja.abril.com.br/tecnologia/vendas-de-tablets-vao-su- perar-as-de-notebooks-nobrasil/ Acesso em 12 out. 2016

NELSON, Robert. Here's why I implanted an NFC chip in my hand disponível em: < https://www.connectedly.com/why-i-implanted-nfc-chip-hand> Acesso em 29 jun. 2017

Graphwear disponível em: <http://graphwear.co> Acesso em 29 jun. 2017

Proteus disponível em: < http://www.proteus.com> Acesso em 29 jun. 2017

DVORSKY,George. What You Need to Know About Getting Magnetic Finger Implants disponível em: < http://io9.gizmodo.com/what-you-need-to-know-about-getting-magnetic-fingerimp-813537993> Acesso em 29 jun. 2017

Aeon Cybernetics abre inscrições para teste de novas modificações corporais disponível em: < http://aeoncybernetics.com/2017/05/05/aeon-cybernetics-abre-inscricoes-para-teste-denovas-modificacoes-corporais/> Acesso em 29 jun. 2017

Futurista prevê que conexão entre o cérebro humano e a inteligência artificial acontecerá nos próximos 15 anos disponível em: < http://aeoncybernetics.com/2017/05/15/futuristapreve-conexao-homem-maquina-15-anos/> Acesso em 29 jun. 2017

VASP - Dicionário Informal disponível em: < http://www.dicionarioinformal.com.br/vasp/> Acesso em 29 jun. 2017

Barometer disponível em: <http://barometer.agorapulse.com> Acesso em 29 jun. 2017 
SANCHEZ, Patricia. LEVIN, Avner. DEL RIEGO, Alissa. Blurred Boundaries: Social Media Privacy and the Twenty-First-Century Employee disponível em: < https://www.researchgate.net/profile/Patricia_Abril/publication/228311105_Blurred_Boundaries_ Social_Media_Privacy_and_the_Twenty-First-

Century_Employee/links/53d7ad290cf2e38c632dde93.pdf> Acesso em 29 jun. 2017

Sensação de anonimato facilita ciberbullying, diz advogado disponível em:< http://www.gazetadopovo.com.br/educacao/vida-na-universidade/vestibular/sensacao-deanonimato-facilita-ciberbullying-diz-advogado-ant28556gmmzsk80lbrctdgsu> Acesso em 29 jun. 2017

REITZ, Guilherme. Mercado Logístico no Brasil: É preciso priorizar uma gestão logística eficiente disponível em: <http://www.logweb.com.br/artigo/mercado-logistico-no-brasil-epreciso-priorizar-uma-gestao-logistica-eficiente/> Acesso em 29 jun. 2017

LEI № 11.196, DE 21 DE NOVEMBRO DE 2005. disponível em: < http://www.planalto.gov.br/ccivil_03/_ato2004-2006/2005/lei/111196.htm> Acesso em 29 jun. 2017

\section{Sobre os autores}

Camila Holanda, PUC-Rio, Brazil <holanda.dsgn@gmail.com>

Marcelo Pereira, PhD, PUC-Rio, Brazil <marcelopereira@me.com> 